\title{
Extracting chemical information from plane wave calculations by a 3D 'fuzzy atoms' analysis
}

\author{
Bako, I ; Stirling, A ; Seitsonen, A P ; Mayer, I
}

\begin{abstract}
Bond order and valence indices have been calculated by the method of the three-dimensional 'fuzzy atoms' analysis, using the numerical molecular orbitals obtained from plane wave DFT calculations, i.e., without introducing any external atom-centered functions. Weight functions of both Hirshfeld and Becke types have been applied. The results are rather close to the similar 'fuzzy atoms' ones obtained by using atom-centered basis sets and agree well with the chemical expectations, stressing the power of the genuine chemical concepts. (C) 2013 Elsevier B. V. All rights reserved.
\end{abstract}

DOI: https://doi.org/10.1016/j.cplett.2013.01.059

Posted at the Zurich Open Repository and Archive, University of Zurich

ZORA URL: https://doi.org/10.5167/uzh-81920

Journal Article

Accepted Version

Originally published at:

Bako, I; Stirling, A; Seitsonen, A P; Mayer, I (2013). Extracting chemical information from plane wave calculations by a 3D 'fuzzy atoms' analysis. Chemical Physics Letters, 563:97-101.

DOI: https://doi.org/10.1016/j.cplett.2013.01.059 


\title{
Extracting Chemical Information from Plane Wave Calculations by a 3D "Fuzzy Atoms" Analysis
}

\author{
I. BAKÓ ${ }^{1}$, A. STIRLING ${ }^{1}$, A. P. SEITSONEN ${ }^{2}$ \\ and \\ I. MAYER ${ }^{1}$ \\ ${ }^{1}$ Institute of Organic Chemistry, Research Centre for Natural Sciences*, \\ Hungarian Academy of Sciences, H-1525 Budapest, P.O. Box 17, Hungary \\ ${ }^{2}$ Physikalisch-Chemisches Institut, Universität Zürich, \\ Winterthurerstrasse 190, CH-8057 Zürich, Switzerland
}

\begin{abstract}
Bond order and valence indices have been calculated by the method of the three-dimensional "fuzzy atoms" analysis, using the numerical molecular orbitals obtained from plane wave DFT calculations, i.e., without introducing any external atom-centered functions. Weight functions of both Hirshfeld and Becke types have been applied. The results are rather close to the similar "fuzzy atoms" ones obtained by using atom-centered basis sets and agree well with the chemical expectations, stressing the power of the genuine chemical concepts.
\end{abstract}

*Formerly called Chemical Research Center. 


\section{Introduction}

In the last decades it has become customary to treat larger and larger molecular systems in an essentially $a b$ initio fashion by using plane wave basis sets, usually combined with some local DFT formalism and appropriate effective potentials replacing core electrons [1]. While the interpretation of the energetic or geometrical quantities does not represent a problem, it is not trivial to connect the results with the genuine chemical concepts. To this end, an auxiliary basis set built from atom-centered functions is sometimes introduced and the molecular orbitals obtained in the plane wave calculations are projected onto these atomic basis functions [2-4]. Recently we have followed an opposite direction, and showed that by using the three-dimensional (3D) "fuzzy atoms" formalism, one can extract the actual effective atomic orbitals from the results of the plane wave calculations [5]. For that reason the molecular orbitals (MOs) were obtained on a 3D grid and were subjected to appropriate unitary transformations that maximized - or, in general, made stationary - the net population of the given orbital in the "fuzzy" region of the selected atom. The procedure does not essentially differ from that applied in the case of using conventional atom-centered basis sets for an analogous calculation of effective atomic orbitals in the "fuzzy atoms" framework [6]. This success inspired us to consider another aspects of the 3D "fuzzy atoms" analysis - the possibility of obtaining chemically relevant quantities, such as bond orders and valences, following the scheme used for atom-centered basis sets [7]. That approach has much in common with recent studies employing Bader's topological theory of "Atoms in Molecules" (AIM) [8,9]. Owing to the complexity of the AIM domains, the "fuzzy atoms" scheme should be simpler (cheaper) and applicable for larger systems.

Accordingly, the aim of this paper is to discuss how one can extract chemical information by using the "fuzzy atoms" approach, i.e., without introducing externally any atom-centered functions, from molecular orbitals obtained in plane wave DFT calculation. It has been found that the results are rather close to those obtained using the similar "fuzzy-atoms" scheme with atom-centered basis sets and agree well with the chemical expectations, stressing the power of the genuine chemical concepts.

\section{Theory}

\subsection{Fuzzy atoms}

The term "fuzzy atoms" analysis means that one decomposes the 3D physical space into atomic regions that do not have sharp boundaries but exhibit a continuous transition from one to another. This is governed by the non- 
negative atomic weight functions $w_{A}(\vec{r})$, assigned to every atom $A$ in every point $\vec{r}$ of the 3D space, in such a manner that one has

$$
w_{A}(\vec{r}) \geq 0 ; \quad \sum_{A} w_{A}(\vec{r})=1,
$$

for each atom and every point of the space. Obviously, $w_{A}(\vec{r})$ should be large "inside" atom $A$ and gradually vanish as the distance from the nucleus $A$ increases.

Actually there are several schemes used to calculate the values of the weight functions $w_{A}(\vec{r})$. In the present study we have used the weight functions of Hirshfeld's "stockholder's" scheme [10], as well as the simple weight function of Becke [11], originally proposed for performing numerical integrations, but serving very well also for the purposes of analysis of chemical nature [7]. Hirshfeld weight functions were obtained from the program CPMD [12] used also for calculating the wave functions (vide infra). These weight functions are computed on the basis of densities of a "protomolecule" in which free atoms are formally put in the positions which the respective atoms occupy in the actual molecule. ${ }^{1}$ A detailed discussion of the algorithm necessary to calculate Becke's weight functions has been given in the Appendix of Ref. 7; here we note only some aspects of it: the Becke functions $w_{A}(\vec{r})$ are simple algebraic functions, having the property that $w_{A}\left(\vec{r}_{A}\right)=1$, $w_{A}\left(\vec{r}_{B}\right)=0,(B \neq A)$, i.e. the weight function for atom $A$ equals one at the "own" nucleus and is zero at the nuclei of other atoms. Another important point is that these weight functions are determined by the pre-defined set of effective atomic radii, but only the ratios of the radii for different pairs of atoms are playing a role. In the present work the classical atomic radii of Slater [14] and Koga [15] have been used.

\subsection{The quantities computed}

\section{Atomic populations}

Dipole moments and atomic populations are easy to calculate. They are also available in the CPMD program using Hirshfeld weights, therefore these quantites were used for testing.

The electron population of atom $A$ is defined as the integral over the respective "fuzzy" atomic domain:

$$
q_{A}^{e}=\int w_{A}(\vec{r}) \varrho(\vec{r}) d v \cong \sum_{i} w_{A}\left(\vec{r}_{i}\right) \varrho\left(\vec{r}_{i}\right)
$$

\footnotetext{
${ }^{1}$ For strongly polar systems it might be worthwhile to use the refined "iterative Hirshfeld scheme" [13], but we do not actually have a code performing such calculations, and the purposes of the present Letter could be achieved without recurring to that much more complex algorithm.
} 
- i.e., the product of the electron density and the weight function of the atom in question is integrated. In practice, of course, the integration is performed numerically, as is indicated above. In the case of a closed-shell electronic system treated by using doubly occupied orbitals $\varphi_{i}(\vec{r})$, the electron density is connected with the MOs through the usual formula

$$
\varrho(\vec{r})=2 \sum_{i}^{o c c}\left|\varphi_{i}(\vec{r})\right|^{2},
$$

but its values can also be obtained directly from the plane wave calculations on a grid (in practice we obtain them in the Gaussian CUBE format). The resulting atomic charge is given, as usual, by the relationship $Q_{A}=Z_{A}-q_{A}^{e}$, where $Z_{A}$ is the effective (valence) nuclear charge (i.e., the original nuclear charge reduced by the charge of core electrons compressed into the effective potential of the atom).

\section{Molecular dipole moments}

The dipole moments have been calculated by the standard formula

$$
\vec{D}=\sum_{A} \vec{R}_{A} Z_{A}-\int \vec{r} \varrho(\vec{r}) d v
$$

by using again the grid representation of electron density for performing the numerical integration. In Eq. (4) $\vec{R}_{A}$ is the radius-vector of nucleus $A$ and $Z_{A}$ is its effective charge defined above. In this study we have calculated dipole moments for testing purposes, only.

\section{Bond orders and valences}

The bond order between atoms $A$ and $B$ defined in the "fuzzy atoms" framework has been given in Ref. 7 as

$$
B_{A B}=\sum_{\mu, \rho}\left[\left(\mathbf{D S}^{A}\right)_{\mu \rho}\left(\mathbf{D S}^{B}\right)_{\rho \mu}+\left(\mathbf{P}^{s} \mathbf{S}^{A}\right)_{\mu \rho}\left(\mathbf{P}^{s} \mathbf{S}^{B}\right)_{\rho \mu}\right] .
$$

In this formula $\mu, \rho$ refer to the orbitals of the basis $\left\{\chi_{\mu}\right\}$ in which the total density matrix $\mathbf{D}$ and spin-density matrix $\mathbf{P}^{s}$ are expressed and $\mathbf{S}^{A}, \mathbf{S}^{B}$ represent the atomic overlap matrices with the elements defined as

$$
S_{\mu \nu}^{A}=\int w_{A}(\vec{r}) \chi_{\mu}^{\star}(\vec{r}) \chi_{\nu}(\vec{r}) d v
$$

In the present case we shall use the molecular orbitals $\varphi_{i}$ as the basis - they are available numerically on a grid. In terms of the MOs the density and spin-density matrices are diagonal, with diagonal elements equal to 2,1 or 0 , 
and 1 or 0 , respectively. Orbitals corresponding to the zero diagonal element need not be considered explicitly, of course. Then, introducing the atomic overlap matrix integrals over the MO-s as

$$
S_{i j}^{A}=\int w_{A}(\vec{r}) \varphi_{i}^{\star}(\vec{r}) \varphi_{j}(\vec{r}) d v
$$

Eq. (5) reduces to

$$
B_{A B}=\sum_{i, j} n_{i} n_{j} S_{i j}^{A} S_{j i}^{B}+\sum_{i, j}^{s . o c c .} S_{i j}^{A} S_{j i}^{B}
$$

where $n_{i}$ is the occupation number of the $\mathrm{MO} \varphi_{i}$ and "s. occ." stands for "singly occupied". (It is assumed, that we are dealing with doubly occupied closed shell orbitals with $n_{i}=2$, and possibly, with some singly occupied ones of spin $\alpha$, for which $n_{i}=1$. The second term in Eq. (8) comes from the term containing the spin-density matrix.) Elements $S_{i j}^{A}$ of the atomic overlap matrices can easily be calculated numerically by summing the products of values $w_{A}, \varphi_{i}$ and $\varphi_{j}$ for all the grid points, like in Eq. (2).

The total valence $V_{A}$ of atom $A$ given in [7] as

$$
V_{A}=2 q_{A}^{e}-\sum_{\mu, \rho}\left(\mathbf{D S}^{A}\right)_{\mu \rho}\left(\mathbf{D S}^{A}\right)_{\rho \mu}
$$

transforms in terms of MO-s to

$$
V_{A}=2 q_{A}^{e}-\sum_{i, j} n_{i} n_{j} S_{i j}^{A} S_{j i}^{A}
$$

For closed-shell wave functions it satisfies the relationship

$$
V_{A}=\sum_{\substack{B \\ B \neq A}} B_{A B}
$$

while in the open-shell case one can introduce the free valence of atom A as the difference

$$
F_{A}=V_{A}-\sum_{\substack{B \\ B \neq A}} B_{A B} .
$$

In the present work only closed-shell systems were considered, so no free valences have been calculated. 


\section{Method of calculations}

The electron structure calculations have been carried out with the CPMD code [12]. We have employed a periodic cubic box of length $15.0 \AA$ and periodic boundary conditions with the Ewald summation method to account for the electrostatic interactions. The test molecules have been placed into the box and their structures have been fully optimized by DFT calculations using the BLYP exchange-correlation functional [16]. A plane-wave basis set with an energy cutoff of 70 Ry has been used to expand the oneelectron orbitals. ${ }^{2}$ Only the valence states have been treated explicitly in the calculations, whereas their interactions with the ionic cores have been described by Troullier-Martins norm-conserving pseudopotentials [16] in the Kleinman-Bylander factorized form [17]. For the 3D fuzzy atom analyses, the Kohn-Sham orbitals of the equilibrated structures have been represented on a discrete grid in Gaussian "cube file" format of $160 \times 160 \times 160$ points corresponding to the dimensions of the box and the cutoff applied. The "cube files" of the MO-s have been obtained also as binary files with no round-off applied; that was necessary to reproduce dipole moments with proper accuracy. The Hirshfeld weight functions have been produced only as standard (formatted) "cube files", but that could hardly lead to any considerable loss of accuracy.

We have calculated the Becke weight functions $w_{A}(\vec{r})$ at every grid point by using the routine of the program described in Ref. 7, exactly as it was done in [5], too. However, here two different sets of atomic radii (Slater's [14] and Koga's [15[) were used in parallel. Similarly to [5], the numerical integrations have been performed simply by performing summations over the grid points, attributing equal weights to every point - the individual MO-s were normalized in the same manner.

For comparison, we have also performed some conventional atom-centered basis set BLYP calculations (with geometry optimization) and subjected them to the "fuzzy atoms" analysis by using the Becke weight functions and Slates atomic radii.

\section{Sample calculations}

Table I summarizes the data obtained for resulting atomic charges and dipole moments for several molecules. The calculated Hirshfeld charges reproduced

\footnotetext{
${ }^{2}$ Test calculations with higher $(100 \mathrm{Ry})$ cutoff show that the calculated quantitites are already converged at this cutoff. Also, test calculations performed by the scheme of Hockney [18] indicate that the effect of the potentials of the "ghost" molecules from neighboring cells is smaller than the accuracy we are pursuing.
} 
perfectly those obtained from the CPMD code. The atomic charges obtained are basically in accord with the chemical expectation, except the probably exaggerated charge separations predicted by the Becke scheme with the Koga radii. (The ratio of the boron and hydrogen radii is practically the same in the Slater's and Koga's sets, hence the corresponding data in the tables are the same, too.) Also, the expected trend of sulfur charges in the dimethyl sulfide $\left(\mathrm{CH}_{3}-\mathrm{S}-\mathrm{CH}_{3}\right)$, dimethyl sulfoxide $\left(\mathrm{CH}_{3}-\mathrm{SO}-\mathrm{CH}_{3}\right)$ and dimethyl sulfone $\left(\mathrm{CH}_{3}-\mathrm{SO}_{2}-\mathrm{CH}_{3}\right)$ molecules - according to which the sulfur atoms with higher formal valency should be more positive - is obtained only with the Hirshfeld scheme. The Becke's formula gives too negative sulfur charges for these molecules. Analogous "fuzzy atoms" results have been obtained also by the conventional calculations applying the standard $6-31 \mathrm{G}^{* *}$ basis set and Slater's radii, which indicates that the use of standard atomic radii, which are kept independent of the chemical environment, is perhaps not adequate for these molecules. (A somewhat similar problem was encountered for fluorine in [7].)

As to dipole moments: we have indicated the experimental values where available [19]; the agreement between the calculated and experimental values may be considered unexpectedly good.

Tables II and III summarize the results obtained for bond orders and valences of the molecules studied. Most numbers are in accord with the classical chemical values. Also their overall behaviour resembles very much that of the "fuzzy atom" results obtained when such an analysis is performed for wave functions resulting from conventional basis set calculations. For instance, the general tendency of getting bond orders between heavy atoms as well as valence numbers somewhat exceeding the respective ideal integer values is common in both cases. In contrast, the conventional "Hilbert-space" valences $[20,21]$ are often somewhat below these ideal values. Even the somewhat striking deviations, such as the large valence values of oxygen atom of dimethyl ether, are very similar to the respective atom-centered basis BLYP values. (For example, using the $6-31 \mathrm{G}^{* *}$ basis, this oxygen atom has "fuzzy atoms" valence 2.95, not far from the value 2.97 shown in Table III.) Such a tendency of oxygen valences exceeding 2 are general for all types of valency calculations; they perhaps can be connected to the existence of some characteristic delocalizations of the lone pair orbitals. Similar observations hold for the sulfur valences. For instance, the "Hilbert space" valence of the formally six-valent sulfurs are usually around 5 while the "fuzzy atoms" ones are around seven. Furthermore the "fuzzy atoms" values do not strongly depend on whether localized or plane wave basis sets are employed. Analogously, the $6-31 \mathrm{G}^{* *}$ Slater valence values of the carbon valences in the $\alpha$-alanine molecule are $4.78,4.57,4.12$, again close to the results in Table III, show- 
ing that these deviations are not connected to the use of plane wave basis and effective potentials, but rather with some peculiarities of the molecule considered and the 3D "fuzzy atoms" analysis used.

The fact that the "fuzzy atoms" valences usually exceed the ideal chemical values may be connected to the fact that this method attributes relatively large secondary bond orders to the pairs of atoms which are not chemically bonded, thus leading to slightly enhanced secondary valence values. Table IV compares selected "fuzzy atoms" total valences calculated by the Hirshfeld scheme whith those values that one obtains if the summation in Eq. (11) is extended only to the nearest neighbouring atoms. It can be seen that the latter are much closer to the expected chemical values.

\section{Conclusions}

The analysis of the results of plane wave calculations discussed here - in full accord with those in $[5,8,9]$ - indicates that plane wave calculations are not only capable to give accurate energies and structural information for molecular systems, but they can also provide connections between the physical and chemical pictures of molecules, quite similar to those one can obtain from calculations using conventional atom-centered basis sets. It is important to stress that the analysis can be done without introducing externally (i.e., artificially) any atom-centered functions, simply by using the numerical representation of the molecular orbitals; in all other aspects the analysis is performed exactly in the same manner as in the case of conventional "LCAO-type" quantum chemical calculations. In the perspective, the method could be extended to truly periodic systems (polymers, surfaces, solid states); while no conceptual complications are expected, a number of technical problems will be necessary to solve, similarly to the case when the bond order calculations have been extended to polymeric systems in the LCAO framework[22]. 


\section{References}

1. D. Marx and J. Hutter, Ab Initio Molecular Dynamics. Basic Theory and advanced Methods, Cambridge University Press, Cambridge 2009.

2. D. Sanchez-Portal, E. Artacho and J. M. Soler, J. of Physics: Condensed Matter, 8 (1996) 3859.

3. M. D. Segall, R. Shah, C. J. Pickard, and M. C. Payne Phys. Rev. B 54 (1996) 16317.

4. B.D. Dunnington and J.R. Schmidt, J. Chem. Theory Comput. 8 (2012) 1902.

5. I. Mayer, I. Bakó and A. Stirling, J. Phys. Chem. A, 115 (2011) 12733.

6. I. Mayer and P. Salvador, J. Chem. Phys. 130 (2009) 234106.

7. I. Mayer and P. Salvador, Chem. Phys. Lett. 383 (2004) 368.

8. G. La Penna, S. Furlan and M. Solà, Theor. Chem. Acc. 130 (2011) 27.

9. A. I. Baranov and M. Kohout, J. Comput. Chem. 32 (2011) 2064.

10. F.L. Hirshfeld, Theor. Chim. Acta 44 (1977) 129.

11. A.D. Becke, J. Chem. Phys. 88 (1988) 2547.

12. CPMD, version 3.15.1, http://www.cpmd.org, Copyright IBM Corp 1990-2006, Copyright MPI für Festkörperforschung Stuttgart 19972001.

13. P. Bultinck, C. Van Alsenoy, P. W. Ayers, and R. Carbó-Dorca, J. Chem. Phys. 126 (2007) 144111.

14. J.C. Slater, J. Chem. Phys. 41 (1964) 3199.

15. Suresh, C.H.; Koga, N. J. Phys. Chem. A 105 (2001), 5940.

16. A. Becke, Phys. Rev. A 38 (1988) 3098;

C. Lee, W. Yang, and R. Parr, Phys. Rev. B 37 (1988) 785.

N. Troullier and J.L. Martins, Phys. Rev. B 43 (1991) 1993.

17. L. Kleinman and D.M. Bylander, Phys. Rev. Lett. 48 (1982) 1425.

18. R. W. Hockney, Methods in Comp. Phys. 9 (1970) 135.

19. CRC Handbook of Chemistry and Physics. 92nd Edition. (W.M. Haynes, editor-in-chief) CRC Press, Boca Raton, Fl, 2011-2012.

20. I. Mayer, Chem. Phys. Lett. 97 (1983) 270.

21. I. Mayer, J. Comput. Chem 28 (2007) 204.

22. I. Mayer, M. Knapp-Mohamaddy and S. Suhai, Chem. Phys. Lett. 389 (2004) 34. 
Table I Dipole moments (in D) and resulting atomic charges for selected molecules. "Slater" and "Koga" refers to results obtained by using Becke's weights with the respective sets of atomic radii. Experimental dipole moments, where available [19], are indicated in parentheses.

\begin{tabular}{|c|c|c|c|c|c|}
\hline \multirow{2}{*}{ Molecule } & \multirow{2}{*}{ Dipole moment } & \multicolumn{4}{|c|}{ Atomic charge } \\
\hline & & & Hirshfeld & Slater & Koga \\
\hline \multirow[t]{2}{*}{ Ethane } & 0 & $\mathrm{C}$ & -0.048 & -0.168 & -0.467 \\
\hline & & $\mathrm{H}$ & 0.016 & 0.056 & 0.155 \\
\hline \multirow[t]{2}{*}{ Ethylene } & 0 & $\mathrm{C}$ & -0.042 & -0.140 & -0.343 \\
\hline & & $\mathrm{H}$ & 0.021 & 0.070 & 0.171 \\
\hline \multirow[t]{2}{*}{ Acetylene } & 0 & $\mathrm{C}$ & -0.069 & -0.228 & -0.275 \\
\hline & & $\mathrm{H}$ & 0.069 & 0.228 & 0.275 \\
\hline \multirow[t]{5}{*}{ trans-Butadiene } & 0 & $\mathrm{C}_{1}$ & -0.002 & -0.134 & -0.336 \\
\hline & & $\mathrm{C}_{2}$ & -0.051 & -0.107 & -0.214 \\
\hline & & $\mathrm{H}\left(\mathrm{C}_{1}\right)$ & 0.016 & 0.072 & 0.174 \\
\hline & & & 0.020 & 0.076 & 0.179 \\
\hline & & $\mathrm{H}\left(\mathrm{C}_{2}\right)$ & 0.017 & 0.093 & 0.196 \\
\hline \multirow[t]{2}{*}{ Cyclobutadiene } & 0 & $\mathrm{C}$ & -0.022 & -0.090 & -0.192 \\
\hline & & $\mathrm{H}$ & 0.022 & 0.090 & 0.192 \\
\hline \multirow[t]{2}{*}{ Benzene } & 0 & $\mathrm{C}$ & -0.016 & -0.089 & -0.190 \\
\hline & & $\mathrm{H}$ & 0.016 & 0.089 & 0.190 \\
\hline \multirow[t]{2}{*}{ Water } & 1.798 & $\mathrm{O}$ & -0.116 & -0.160 & -0.396 \\
\hline & $(1.79)$ & $\mathrm{H}$ & 0.058 & 0.080 & 0.198 \\
\hline \multirow[t]{4}{*}{ Dimethyl ether } & 1.264 & $\mathrm{C}$ & -0.037 & -0.169 & -0.453 \\
\hline & $(1.3)$ & $\mathrm{O}$ & 0.009 & -0.049 & -0.074 \\
\hline & & $\mathrm{H}(2 \times)$ & 0.008 & 0.060 & 0.159 \\
\hline & & $H(1 \times)$ & 0.016 & 0.074 & 0.172 \\
\hline \multirow[t]{5}{*}{ Acetone } & 2.883 & $\mathrm{C}\left(\mathrm{CH}_{3}\right)$ & -0.070 & -0.142 & -0.428 \\
\hline & $(2.91)$ & $\mathrm{C}(\mathrm{CO})$ & 0.137 & -0.135 & -0.157 \\
\hline & & $\mathrm{O}$ & -0.149 & -0.094 & -0.102 \\
\hline & & $\mathrm{H}(2 \times)$ & 0.028 & 0.093 & 0.193 \\
\hline & & $\mathrm{H}(1 \times)$ & 0.023 & 0.071 & 0.172 \\
\hline
\end{tabular}


Table I (Continued)

\begin{tabular}{|c|c|c|c|c|c|}
\hline \multirow{2}{*}{ Molecule } & \multirow{2}{*}{ Dipole moment } & \multicolumn{4}{|c|}{ Atomic charge } \\
\hline & & & Hirshfeld & Slater & Koga \\
\hline$\alpha$-Alanine & 2.280 & $\begin{array}{c}\mathrm{C}_{1}(\mathrm{COOH}) \\
\mathrm{C}_{\alpha} \\
\mathrm{C}_{\beta} \\
\mathrm{O}(\mathrm{O}=) \\
\mathrm{O}(\mathrm{OH}) \\
\mathrm{N} \\
\mathrm{H}(\mathrm{OH}) \\
\mathrm{H}\left(\mathrm{NH}_{2}\right) \\
\mathrm{H}\left(\mathrm{C}_{\alpha}\right) \\
\mathrm{H}\left(\mathrm{C}_{\beta}\right)\end{array}$ & $\begin{array}{r}0.099 \\
0.035 \\
-0.065 \\
-0.146 \\
-0.013 \\
-0.108 \\
0.068 \\
0.054 \\
0.028 \\
0.005 \\
0.013 \\
0.021 \\
0.012\end{array}$ & $\begin{array}{r}-0.205 \\
-0.150 \\
-0.156 \\
-0.107 \\
-0.012 \\
-0.134 \\
0.163 \\
0.102 \\
0.123 \\
0.117 \\
0.082 \\
0.071 \\
0.084\end{array}$ & $\begin{array}{r}-0.217 \\
-0.283 \\
-0.451 \\
-0.124 \\
-0.101 \\
-0.299 \\
0.282 \\
0.204 \\
0.229 \\
0.219 \\
0.184 \\
0.171 \\
0.186\end{array}$ \\
\hline Dimethyl sulfide & $\begin{array}{l}1.543 \\
(1.5)\end{array}$ & $\begin{array}{c}\mathrm{C} \\
\mathrm{S} \\
\mathrm{H}(2 \times) \\
\mathrm{H}(1 \times)\end{array}$ & $\begin{array}{r}-0.069 \\
0.018 \\
0.018 \\
0.025\end{array}$ & $\begin{array}{r}0.153 \\
-0.638 \\
0.058 \\
0.048\end{array}$ & $\begin{array}{r}-0.152 \\
-0.578 \\
0.150 \\
0.140\end{array}$ \\
\hline Dimethyl sulfoxide & $\begin{array}{l}3.873 \\
(3.96)\end{array}$ & $\begin{array}{l}\mathrm{C} \\
\mathrm{S} \\
\mathrm{O} \\
\mathrm{H} \\
\mathrm{H} \\
\mathrm{H}\end{array}$ & $\begin{array}{r}-0.083 \\
0.279 \\
-0.266 \\
0.027 \\
0.024 \\
0.028\end{array}$ & $\begin{array}{r}-0.004 \\
-0.508 \\
-0.074 \\
0.098 \\
0.088 \\
0.100\end{array}$ & $\begin{array}{r}-0.301 \\
-0.412 \\
-0.116 \\
0.189 \\
0.181 \\
0.194\end{array}$ \\
\hline Dimethyl sulfone & $\begin{array}{c}4.47 \\
(4.44)\end{array}$ & $\begin{array}{c}\mathrm{C} \\
\mathrm{S} \\
\mathrm{O} \\
\mathrm{H}(2 \times) \\
\mathrm{H}(1 \times)\end{array}$ & $\begin{array}{r}-0.080 \\
0.403 \\
-0.222 \\
0.033 \\
0.036\end{array}$ & $\begin{array}{r}0.017 \\
-0.822 \\
0.063 \\
0.106 \\
0.119\end{array}$ & $\begin{array}{r}-0.278 \\
-0.577 \\
-0.046 \\
0.201 \\
0.211\end{array}$ \\
\hline Diborane & 0 & $\begin{array}{c}\text { B } \\
\mathrm{H}(\mathrm{br} .) \\
\mathrm{H}(\text { term. })\end{array}$ & $\begin{array}{r}0.051 \\
0.045 \\
-0.048\end{array}$ & $\begin{array}{r}-0.454 \\
0.257 \\
0.098\end{array}$ & $\begin{array}{r}-0.453 \\
0.257 \\
0.098\end{array}$ \\
\hline
\end{tabular}


Table II Bond orders for selected molecules.

\begin{tabular}{|c|c|c|c|c|}
\hline \multirow{2}{*}{ Molecule } & \multicolumn{4}{|c|}{ Bond order } \\
\hline & & Hirshfeld & Slater & Koga \\
\hline \multirow[t]{2}{*}{ Ethane } & $\mathrm{C}-\mathrm{C}$ & 1.042 & 1.139 & 1.212 \\
\hline & $\mathrm{C}-\mathrm{H}$ & 0.961 & 0.947 & 0.928 \\
\hline \multirow[t]{2}{*}{ Ethylene } & $\mathrm{C}-\mathrm{C}$ & 1.831 & 1.964 & 2.032 \\
\hline & $\mathrm{C}-\mathrm{H}$ & 0.997 & 0.959 & 0.922 \\
\hline \multirow[t]{2}{*}{ Acetylene } & $\mathrm{C}-\mathrm{C}$ & 2.740 & 2.831 & 2.875 \\
\hline & $\mathrm{C}-\mathrm{H}$ & 1.050 & 0.948 & 0.935 \\
\hline \multirow[t]{5}{*}{ Butadiene } & $\mathrm{C}_{1}-\mathrm{C}_{2}$ & 1.708 & 1.802 & 1.846 \\
\hline & $\mathrm{C}_{2}-\mathrm{C}_{3}$ & 1.179 & 1.207 & 1.223 \\
\hline & $\mathrm{C}_{1}-\mathrm{H}$ & 1.000 & 0.961 & 0.923 \\
\hline & & 0.990 & 0.950 & 0.911 \\
\hline & $\mathrm{C}_{2}-\mathrm{H}$ & 0.952 & 0.913 & 0.871 \\
\hline \multirow[t]{3}{*}{ Cyclobutadiene } & $\mathrm{C}-\mathrm{C}$ & 1.013 & 1.014 & 1.021 \\
\hline & $\mathrm{C}=\mathrm{C}$ & 1.784 & 1.862 & 1.888 \\
\hline & $\mathrm{C}-\mathrm{H}$ & 0.991 & 0.951 & 0.908 \\
\hline \multirow[t]{2}{*}{ Benzene } & $\mathrm{C}-\mathrm{C}$ & 1.390 & 1.432 & 1.455 \\
\hline & $\mathrm{C}-\mathrm{H}$ & 0.973 & 0.930 & 0.888 \\
\hline Water & $\mathrm{O}-\mathrm{H}$ & 1.319 & 1.196 & 1.095 \\
\hline \multirow[t]{3}{*}{ Dimethyl ether } & $\mathrm{C}-\mathrm{O}$ & 1.232 & 1.299 & 1.329 \\
\hline & $\mathrm{C}-\mathrm{H}(1 \times)$ & 0.967 & 0.941 & 0.913 \\
\hline & $\mathrm{C}-\mathrm{H}(2 \times)$ & 0.955 & 0.930 & 0.903 \\
\hline \multirow[t]{4}{*}{ Acetone } & $\mathrm{C}-\mathrm{C}$ & 1.035 & 1.076 & 1.112 \\
\hline & $\mathrm{C}-\mathrm{O}$ & 2.158 & 2.194 & 2.194 \\
\hline & $\mathrm{C}-\mathrm{H}(2 \times)$ & 0.948 & 0.917 & 0.889 \\
\hline & $\mathrm{C}-\mathrm{H}(1 \times)$ & 0.957 & 0.938 & 0.909 \\
\hline
\end{tabular}

Continued 
Table II (Continued)

\begin{tabular}{|c|c|c|c|c|}
\hline \multirow{2}{*}{ Molecule } & \multicolumn{4}{|c|}{ Bond order } \\
\hline & & Hirshfeld & Slater & Koga \\
\hline \multirow[t]{11}{*}{$\alpha$-Alanine } & $\mathrm{C}_{1}-\mathrm{C}_{\alpha}$ & 0.981 & 0.997 & 1.009 \\
\hline & $\mathrm{C}_{\alpha}-\mathrm{C}_{\beta}$ & 0.976 & 1.041 & 1.085 \\
\hline & $\mathrm{C}-\mathrm{N}$ & 1.133 & 1.201 & 1.247 \\
\hline & $\mathrm{C}=\mathrm{O}$ & 2.143 & 2.166 & 2.169 \\
\hline & $\mathrm{C}-\mathrm{O}$ & 1.394 & 1.459 & 1.482 \\
\hline & $\mathrm{O}-\mathrm{H}$ & 1.167 & 1.023 & 0.917 \\
\hline & $\mathrm{C}_{\alpha}-\mathrm{H}$ & 0.901 & 0.862 & 0.821 \\
\hline & $\mathrm{C}_{\beta}-\mathrm{H}(2 \times)$ & 0.955 & 0.927 & 0.896 \\
\hline & $\mathrm{C}_{\beta}-\mathrm{H}(1 \times)$ & 0.950 & 0.933 & 0.904 \\
\hline & $\mathrm{N}-\mathrm{H}$ & 1.098 & 1.012 & 0.945 \\
\hline & & 1.083 & 0.986 & 0.916 \\
\hline \multirow[t]{3}{*}{ Dimethyl sulfide } & $\mathrm{C}-\mathrm{S}$ & 1.192 & 1.203 & 1.283 \\
\hline & $\mathrm{C}-\mathrm{H}(2 \times)$ & 0.961 & 0.913 & 0.893 \\
\hline & $\mathrm{C}-\mathrm{H}(1 \times)$ & 0.961 & 0.926 & 0.892 \\
\hline \multirow[t]{4}{*}{ Dimethyl sulfoxide } & $\mathrm{C}-\mathrm{S}$ & 1.052 & 1.089 & 1.164 \\
\hline & $\mathrm{S}=\mathrm{O}$ & 2.165 & 2.156 & 2.291 \\
\hline & C-H $(2 \times)$ & 0.958 & 0.914 & 0.886 \\
\hline & $\mathrm{C}-\mathrm{H}(1 \times)$ & 0.949 & 0.906 & 0.885 \\
\hline \multirow[t]{4}{*}{ Dimethyl sulfone } & $\mathrm{C}-\mathrm{S}$ & 0.975 & 1.067 & 1.091 \\
\hline & $\mathrm{S}=\mathrm{O}$ & 2.144 & 2.321 & 2.292 \\
\hline & $\mathrm{C}-\mathrm{H}(2 \times)$ & 0.953 & 0.902 & 0.878 \\
\hline & $\mathrm{C}-\mathrm{H}(1 \times)$ & 0.944 & 0.890 & 0.867 \\
\hline \multirow[t]{3}{*}{ Diborane } & $\mathrm{B}-\mathrm{H}_{b r}$ & 0.501 & 0.455 & 0.455 \\
\hline & $\mathrm{B}-\mathrm{H}_{t e r m}$ & 0.901 & 0.932 & 0.932 \\
\hline & B-B & 0.719 & 0.892 & 0.892 \\
\hline
\end{tabular}




\section{Table III}

Valences for selected molecules.

\begin{tabular}{|c|c|c|c|c|}
\hline \multirow{2}{*}{ Molecule } & \multicolumn{4}{|c|}{ Valence } \\
\hline & & Hirshfeld & Slater & Koga \\
\hline \multirow[t]{2}{*}{ Ethane } & $\mathrm{C}$ & 4.216 & 4.155 & 4.137 \\
\hline & $\mathrm{H}$ & 1.285 & 1.109 & 1.105 \\
\hline \multirow[t]{2}{*}{ Ethylene } & $\mathrm{C}$ & 4.141 & 4.050 & 4.024 \\
\hline & $\mathrm{H}$ & 1.281 & 1.105 & 1.041 \\
\hline \multirow[t]{2}{*}{ Acetylene } & $\mathrm{C}$ & 3.979 & 3.877 & 3.888 \\
\hline & $\mathrm{H}$ & 1.252 & 1.054 & 1.017 \\
\hline \multirow[t]{5}{*}{ Butadiene } & $\mathrm{C}_{1}$ & 4.440 & 4.274 & 4.276 \\
\hline & $\mathrm{C}_{2}$ & 4.162 & 4.053 & 4.023 \\
\hline & $\mathrm{H}\left(\mathrm{C}_{1}\right)$ & 1.296 & 1.105 & 1.042 \\
\hline & & 1.292 & 1.123 & 1.039 \\
\hline & $\mathrm{H}\left(\mathrm{C}_{2}\right)$ & 1.285 & 1.116 & 1.023 \\
\hline \multirow[t]{2}{*}{ Cyclobutadiene } & $\mathrm{C}$ & 4.337 & 4.151 & 4.141 \\
\hline & $\mathrm{H}$ & 1.281 & 1.096 & 1.031 \\
\hline \multirow{2}{*}{ Benzene } & $\mathrm{C}$ & 4.457 & 4.251 & 4.246 \\
\hline & $\mathrm{H}$ & 1.288 & 1.090 & 1.026 \\
\hline \multirow[t]{2}{*}{ Water } & $\mathrm{O}$ & 2.639 & 2.392 & 2.145 \\
\hline & $\mathrm{H}$ & 1.449 & 1.270 & 1.146 \\
\hline \multirow[t]{4}{*}{ Dimethyl ether } & $\mathrm{C}$ & 4.320 & 4.280 & 4.247 \\
\hline & $\mathrm{O}$ & 3.135 & 2.973 & 2.998 \\
\hline & $\mathrm{H}(1 \times)$ & 1.288 & 1.090 & 1.032 \\
\hline & $\mathrm{H}(2 \times)$ & 1.292 & 1.103 & 1.041 \\
\hline \multirow[t]{5}{*}{ Acetone } & $\mathrm{C}\left(\mathrm{CH}_{3}\right)$ & 4.202 & 4.092 & 4.056 \\
\hline & $\mathrm{C}(\mathrm{CO})$ & 4.821 & 4.715 & 4.750 \\
\hline & $\mathrm{O}$ & 2.733 & 2.597 & 2.602 \\
\hline & $\mathrm{H}(2 \times)$ & 1.289 & 1.096 & 1.030 \\
\hline & $\mathrm{H}(1 \times)$ & 1.296 & 1.107 & 1.043 \\
\hline
\end{tabular}

Continued 
Table III (Continued)

\begin{tabular}{|c|c|c|c|c|}
\hline \multirow{2}{*}{ Molecule } & \multicolumn{4}{|c|}{ Valence } \\
\hline & & Hirshfeld & Slater & Koga \\
\hline \multirow[t]{12}{*}{$\alpha$-Alanine } & $\mathrm{C}_{1}(\mathrm{COOH})$ & 5.075 & 4.995 & 5.072 \\
\hline & $\mathrm{C}_{\alpha}$ & 4.721 & 4.595 & 4.641 \\
\hline & $\mathrm{C}_{\beta}$ & 4.233 & 4.132 & 4.106 \\
\hline & $\mathrm{O}(\mathrm{O}=)$ & 2.791 & 2.641 & 2.647 \\
\hline & $\mathrm{O}(\mathrm{OH})$ & 3.021 & 2.860 & 2.794 \\
\hline & $\mathrm{N}$ & 3.741 & 3.522 & 3.444 \\
\hline & $\mathrm{H}(\mathrm{OH})$ & 1.461 & 1.177 & 1.046 \\
\hline & $\mathrm{H}\left(\mathrm{C}_{\alpha}\right)^{\prime}$ & 1.330 & 1.072 & 1.003 \\
\hline & $\mathrm{H}\left(\mathrm{C}_{\beta}\right)(2 \times)$ & 1.303 & 1.097 & 1.032 \\
\hline & $(1 \times)$ & 1.289 & 1.105 & 1.042 \\
\hline & $\mathrm{H}(\mathrm{N})$ & 1.380 & 1.171 & 1.080 \\
\hline & & 1.445 & 1.163 & 1.062 \\
\hline \multirow[t]{4}{*}{ Dimethyl sulfide } & $\mathrm{C}$ & 4.199 & 4.019 & 4.053 \\
\hline & S & 3.181 & 3.027 & 3.071 \\
\hline & $\mathrm{H}(2 \times)$ & 1.299 & 1.102 & 1.044 \\
\hline & $\mathrm{H}(1 \times)$ & 1.291 & 1.097 & 1.041 \\
\hline \multirow[t]{5}{*}{ Dimethyl sulfoxide } & $\mathrm{C}$ & 4.181 & 4.023 & 4.029 \\
\hline & S & 4.935 & 4.849 & 5.083 \\
\hline & $\mathrm{O}$ & 2.618 & 2.488 & 2.607 \\
\hline & $\mathrm{H}(2 \times)$ & 1.303 & 1.096 & 1.039 \\
\hline & $\mathrm{H}(1 \times)$ & 1.291 & 1.063 & 1.034 \\
\hline \multirow[t]{5}{*}{ Dimethyl sulfone } & $\mathrm{C}$ & 4.173 & 4.019 & 4.001 \\
\hline & S & 6.844 & 7.295 & 7.205 \\
\hline & $\mathrm{O}$ & 2.696 & 2.711 & 2.696 \\
\hline & $\mathrm{H}(2 \times)$ & 1.291 & 1.085 & 1.025 \\
\hline & $H(1 \times)$ & 1.299 & 1.079 & 1.018 \\
\hline \multirow{3}{*}{ Diborane } & B & 3.674 & 3.744 & 3.744 \\
\hline & $\mathrm{H}_{b r}$ & 1.305 & 1.026 & 1.026 \\
\hline & $\mathrm{H}_{\text {term }}$ & 1.182 & 0.993 & 0.993 \\
\hline
\end{tabular}




\section{Table IV}

Total and nearest neighbour valences for selected molecules obtained by Hirshfeld weights.

\begin{tabular}{|cccc|}
\hline \multirow{2}{*}{ Molecule } & Atom & \multicolumn{2}{c|}{ Valence } \\
\cline { 3 - 4 } & & Total & Nearest neighb. \\
\hline \multirow{2}{*}{ Ethylene } & $\mathrm{C}$ & 4.141 & 3.828 \\
Butadiene & $\mathrm{C}_{1}$ & 4.440 & 3.831 \\
Cyclobutadiene & $\mathrm{C}_{2}$ & 4.162 & 3.692 \\
Benzene & $\mathrm{C}$ & 4.337 & 3.788 \\
Dimethyl ether & $\mathrm{C}$ & 4.457 & 3.752 \\
& $\mathrm{C}$ & 4.320 & 4.115 \\
Acetone & $\mathrm{O}$ & 3.135 & 2.463 \\
& $\mathrm{C}(\mathrm{CH})$ & 4.202 & 3.887 \\
Dimethyl sulfide & $\mathrm{CO})$ & 4.821 & 4.228 \\
& $\mathrm{O}$ & 2.733 & 2.158 \\
Dimethyl sulfoxide & $\mathrm{C}$ & 4.199 & 4.071 \\
& $\mathrm{~S}$ & 3.181 & 2.384 \\
& $\mathrm{C}$ & 4.181 & 3.918 \\
Dimethyl sulfone & $\mathrm{S}$ & 4.935 & 4.276 \\
& $\mathrm{O}$ & 2.618 & 2.166 \\
& $\mathrm{C}$ & 4.173 & 3.826 \\
& $\mathrm{O}$ & 6.844 & 6.236 \\
& $\mathrm{O}$ & 2.696 & 2.144 \\
\hline
\end{tabular}

